\title{
Formation of Educational Ecosystem as a Key Priority of the Russian Education Development Strategy
}

\author{
Larisa D. Kozyreva ${ }^{1 *[O R C I D}$ 0000-0002-7238-6817], \\ Alexsander I. Kotov 1[ORCID 0000-0002-1810-7741] \\ Natalia D. Morozova 1[ORCID 0000-0001-5807-9274], \\ Natalya V. Alexandrova 2[ORCID 0000-0001-9115-0378], \\ Elena V. Migunova 2[ORCID 0000-0003-1997-617X]
}

${ }^{1}$ North-West Institute of Management, The Russian Presidential Academy of National Economy and Public Administration (RANEPA), Saint Petersburg, Russia

${ }^{2}$ Yaroslav-the-Wise Novgorod State University, Veliky Novgorod, Russia

kozyreva-ld@ranepa.ru

\begin{abstract}
The article analyzes the educational ecosystem in the context of the strategic development of education. The purpose of the article is to study the experience of implementing the ecosystem approach while organizing the educational process in accordance with the challenges of the emerging information society. The article presents the basic features of the educational ecosystem and briefly describes the major changes in educational activities: the integrative nature of the content of teaching methods and tools; adaptability, co-evolution of the environment and its subjects; the theory of connectivism dwelling upon learning in the digital age. Referring to the research by V.L. Kvint and O.E. Permyakov, the authors conclude that the ecosystem approach is an essential factor for the strategic development of education. In their research, N.V. Dyorina, L.I. Savva, N.I. Rabina identified the peculiarities of forming the university innovative ecosystems. Particular attention is paid to the ideas of S. Panda on methods for studying the digital footprint of students and the use of cluster analysis of the obtained data for taking the managerial decisions. A paradigm approach, the theory of strategizing and learning models in the context of digital transformation were used during the analysis of the ecosystem approach to the educational system. The analysis of various research positions led to the conclusion that the transformation of the educational environment of a university into an eco-educational one is a comprehensive problem; its solution is in the development of an appropriate theory of education and of a corresponding eco-educational model. The article has considerable practical value because it contains recommendations and suggests approaches that can be taken into account when modernizing educational activities in higher education institutions: a step-by-step transition to the implementation of changes is necessary through the strategic planning of the development of structures and processes in the educational ecosystem of the university with the help of digital innovative technologies used for education and educational management.
\end{abstract}

Keywords: information society, strategic priority, educational ecosystem, paradigm approach

\section{INTRODUCTION}

The emergence of an information society in Russia is a complex, contradictory and uncertain process.

The given research is based on the interpretation of the "information society" concept according to the "Strategy for the development of the information society in the Russian Federation for 2017-2030", where "information society" is defined as a postindustrial society, a new historical phase in the development of civilization, in which the main 
products are information and knowledge as its acme [1].

The research problem is in the need to resolve the contradiction between the educational system generated by the industrial revolution and successfully coping with its tasks for several past decades, and fundamentally new challenges that this system is unable to respond to. These challenges are driven by the need to:

- ensure the availability of any form of education, mitigating the manifestations of educational inequality;

- guarantee the possibility of lifelong learning;

- provide an individual approach at each stage of the educational process, bringing it as close as possible to the needs and abilities of the student;

- respond to the demands of the rapidly changing labor market flexibly, quickly and properly.

One of these responses to the challenges of the emerging information society was the idea, and then the theory of the educational ecosystem. The present research consider educational ecosystem as an integrative environment of interaction based on the exchange of data among all educational relations participants; this environment has variable adaptive educational content, innovative products, technologies and other elements; it ensures personal safety, the implementation of the required standards, the development of the 21 st century skills, the values of civil society, personal, social and professional self-realization in a network society and a multinational state [2]. There are studies that determine the basic features of the educational ecosystem. These include:

- versatility, implying an integrative nature of content, methods, teaching aids and alternative sources of knowledge, united by various ties;

- independent actors of the educational ecosystem (students, parents, teachers, community members, professionals, scientists, researchers, librarians, administrators, tutors, consultants, etc.) who are constantly adapting self-organizing parts of a single whole;

- there is a shift from a single platform (both physical and virtual) to the network (both physical and virtual);
- ecosystems provide all the opportunities for the development of each person and at the same time for the development of the collective mind or, according to the theory of connectivism, the mind of the crowd;

- co-evolution of the environment and its subjects, i.e. mutual enrichment and mutual development;

- the core, the center of the educational ecosystem is a student with its psychophysical individual characteristics, life and educational needs; the subjects of education are individuals of different ages, representatives of different countries, religions, worldviews and cultures;

- adaptability to the needs of each subject and self-organization, self-regulation of energy and information exchange processes [3].

The fundamental works that generalize the practice of the educational ecosystem emergence and development are those by O.E. Permyakov and E.A. Kitin. Using the example of the educational ecosystem of the North-West Institute of Management, The Russian Presidential Academy of National Economy and Public Administration, RANEPA (Saint Petersburg, Russia), they show that the methodology of strategic planning for the development of educational ecosystems allows creating better development models than the generally accepted models of educational process management; working out an "ecosystem" strategy for the development of an educational organization; avoiding costs and misappropriation of resources in the context of digital transformation and dynamic changes in social relations [4].

There is the research on the problem of multifactorial management of the development of innovative educational ecosystems of universities as a complex, multi-level educational community of participants acting within the framework of existing institutional norms and, at the same time, implementing development projects aimed at creating new social institutions [5].

N.V. Dyorina, L.I. Savva, and E.I. Rabina dwell upon the formation of university ecosystems. The researchers argue that transformational processes in an eco-educational university environment inevitably lead to the creation of innovative ecosystems.

University innovative ecosystems make it possible to unite the university research activities 
and design, educational and entrepreneurial activities into a joint network of cooperation [6].

The topic of the educational ecosystem is a new development; the recent publication of the report "Educational Ecosystems: Emerging Practices for Future Education" can be considered its starting point. Educational ecosystems are defined as networks of interconnected and diverse subjects participating in the process of learning, upbringing, and development throughout life [7].

The COVID-19 pandemic has affected the format of university education; the digital learning environment is developing at an accelerated pace. The willingness of teachers to use information technology, create electronic educational resources, use massive open online courses, work on Learning Management System (LMS) platforms determines the quality of the educational process. Soft skills have become significant for both students and teachers. The development of cooperation skills [8] is a prerequisite for joint learning activities. The teacher acts as a facilitator, which has a positive impact and stimulates online student group work.

Models of learning in the context of digital transformation determine the methods for studying the student's digital footprint [9]. The comprehensive analysis of problems associated with digital transformation in education was given by Prof. S. Panda [10]. The topic of the digital footprint has been actively discussed for more than two years, an attempt has been made to develop a single standard, but there is still no consensus on this issue [11].

One of the possible algorithms for analyzing digital footprint is the use of cluster data analysis. During the research, one should form systems of signs [12], for example, time spent in the training system, opening (downloading) documents, frequency of visits, average time and variance of visits, reading various content, completing assignments, tests, timing. Formation of metrics on these grounds is an intermediate task. The subsequent task is a stable (in regards to various metrics) division into clusters. Correlation of dynamics during the cluster analysis will help better understand the process of making managerial decisions in the educational process.

The 21 st century university faces the challenge of changing its focus from transmitting to shaping learning and teaching contexts. In regards to university institutions, it is crucial to choose those new forms of learning, teaching, content selection, implementation, usage and organization that generate important knowledge for the planet, for the professional and living environment, and for individuals [13].

\section{MATERIALS AND METHODS}

The research methodology is two-pronged.

First of all, there is an ecosystem approach to the educational system; it emerged as a response to the challenges of the new information society and led to a change in methodological approaches (paradigms) in pedagogy.

For a long time, the "knowledge" paradigm was dominating the science. It has not disappeared yet. In his theory of paradigms, T. Kuhn described a significant time period when a new emerging paradigm peacefully coexists with the previous one, which is being replaced; it happens despite the presence of facts that cannot be explained within the framework of the previous paradigm still existing "by inertia".

The application of the paradigm approach to the analysis of the educational system allows one to conclude that there is a transition from a "knowledge" paradigm to a new one, which a number of works refer to as "humanistic". In pedagogy, network-centric and ecosystem methodological approaches emerged. N.Yu. Fominykh, E.I. Koikova, A.V. Bubenchikova reveals in detail the essence of these methodological approaches in [3].

The second, no less important, methodological foundation of the given research is the theory of strategizing. In recent years, a significant breakthrough has occurred in the development of this theory due to the efforts of V.L. Kvint who established the scientific school of strategizing $[14,15]$.

It should be noted that the research carried out within the framework of this school has become a relevant response to the demands of management practice and the challenges of innovative development [16].

Our research strongly relies on an interview given by V.L. Kvint on the problem of choosing priorities. In this interview, the scientist emphasizes a seemingly obvious idea: with a shortage of resources, it is necessary to select priorities carefully. Moreover, these priorities should guarantee a breakthrough: you need to choose only those of them that contain competitive advantages, those that Russia can achieve more efficiently and faster than competitors [17]. 
There is a noteworthy experience of American colleagues in building an educational ecosystem [18]. The researchers interviewed thirty ecosystem participants from US universities, the transcripts of those interviews were encoded using a three-step process, including open, axial, selective coding, and later they were analyzed using the justified theory. It was found out that (i) the key elements of the university entrepreneurship education ecosystem consist of six units (colleges and universities, students, teachers, government, industry and community) acting as initiators and seven factors (entrepreneurship curriculum, entrepreneurial activity and internships, organizational structure, resources, leadership vision, faculty members and working mechanism) acting as facilitators; (ii) these key elements constitute three independent functional subsystems, namely education and innovation, support and management, which are linked by universities; (iii) the process of developing a university-based entrepreneurship education ecosystem has seven stages: preparation, germination, growth, equilibrium, stagnation, recession and collapse.

Noteworthy is the ecosystem built on the basis of Internet of Things (IoT) devices [19]; such structure is generic and scalable, encompassing multistakeholder partnerships, learning outcomes, curriculum design and technical architecture. The authors emphasize the importance of incorporating data-driven thinking into the core of the learning environment as it leads to collaborative learning and the development of specific skills such as problem finding and solving, cognitive, analytical thinking, spatial skills, mental manipulation of objects, organization, leadership, management, etc.

One of the main advantages of digital learning is the ability to build an individual learning path; there is a research on this topic [20], its purpose was to study the attitude of teachers and the problems they face in connection with the individual educational program (IEP).

Organization of educational space within the framework of the ecosystem approach requires digital transformation of institutions [21]. From a managerial point of view, the success of digital transformation is determined by the effective business models. To ensure sustainability, university leaders and policymakers are provided with proposals for a solid foundation, ongoing investment and ongoing monitoring to enhance the contribution of higher education to social and economic development [13].
This methodological foundation allows defining the forming of an "educational ecosystem" as one of the key priorities of the Strategy for the Development of Russian Education.

\section{RESULTS}

The analysis of various research standpoints led to the conclusion that the content of the key concept "educational ecosystem" has undergone a certain evolution. At the beginning of the century, the educational ecosystem was considered mainly as a system of support for education, as a set of technologies (social networks and digital platforms); later, there was a transition from the concept of "educational environment" understood as the space where knowledge was acquired, skills and abilities were formed to the concept of "educational ecosystem".

We agree with E.A. Shmeleva, who believes that the transformation of the educational environment of a university into an eco-educational one is a comprehensive problem, the solution of which requires, first of all, scientific support [22].

The educational ecosystem is a tool aimed at ensuring the competitiveness of both single educational organizations and certain territories. This fact further increases the importance of forming the educational ecosystem.

Defining the process of "educational ecosystem" formation as a key priority of the Strategy for the Development of Russian Education and the concentration of resources in this area will allow using the competitive advantages of the national education system.

Digital educational systems are becoming environments for a digital learning, sharing experience, shaping the value attitudes of students and teachers. There is not only a replacement of tools and methods of teaching, but also the introduction of digital analytical systems that make it possible to quickly assess and ensure the quality of education.

To improve the quality of education through the use of digital innovative technologies of teaching and educational management, to ensure the development of the educational ecosystem, it is necessary to integrate new and existing digital educational resources, to introduce intelligent solutions for the unified digital administration of information flows at all levels and for all types of education (training) based on data from automated 
monitoring of educational achievements, the formation of competencies, assessment of the quality of education and the effectiveness of educational management.

A new ecosystem approach means the organization of the activities of numerous partners, structures and processes in the educational ecosystem of the university as a single organism - a community of various participants of educational and related processes.

The digital transformation of the educational ecosystem of the university involves the creation of development institutions in the following areas:

- digital management of the education quality and of the educational ecosystem development;

- competence management, educational support and support for career growth;

- digital monitoring of educational statistics and the effectiveness of educational management;

- scientific, informational and methodological support for the creation and implementation of innovative educational programs, courses;

- scientific and methodological, regulatory, organizational and technological support of digital transformation and development of the educational ecosystem;

- the anticipatory training of professionals to solve the problems of digital transformation of the university educational ecosystem.

\section{DISCUSSION}

At the beginning of the 21 st century, the concept of "educational ecosystem" acquired a new meaning. Now it means an educational ecosystem that corresponds to the goals and objectives of modern education and takes into account the peculiarities of the information society.

The transformation of the university educational environment into an eco-educational one is a comprehensive problem, the solution of which requires, first of all, scientific support, i.e., the development of an appropriate theory of education and an eco-educational model in accordance with it.

By the eco-educational model, we mean a set of principles and approaches that reflect the main patterns of development of the systems comprising the educational process and determining its direction, content, forms and methods, as well as the peculiarities of its management. The educational ecosystem should be built on the principles laid down in the concept of sustainable development of Russian education.

\section{CONCLUSION}

The conducted research proves the validity of the thesis that the formation of the educational ecosystem should become one of the important priorities of the Strategy for the development of national education. This priority will allow implementing the competitive advantages of the Russian traditional and modern education system, ensuring its success in the educational sphere competition.

The research is practice-oriented and has significant research prospects of revealing the essence and content of the competitive advantages of the national educational ecosystem; determining the main directions and prospects for their implementation.

\section{AUTHORS' CONTRIBUTIONS}

The research concept and design are done by Larisa D. Kozyreva. Text is written by Larisa D. Kozyreva, Natalia D. Morozova. Editing is performed by Alexsander I. Kotov, Natalya V. Alexandrova, and Elena V. Migunova.

\section{REFERENCES}

[1] "Strategy for the development of the information society in the Russian Federation for 2017-2030 (draft)" [Strategiya razvitiya informatsionnogo obshchestva $\mathrm{v}$ Rossiyskoy Federatsii na 2017-2030 gody (proekt)], 2017. (In Russ.). Retrieved from https://drussia.ru/wp-content/uploads/2016/12/2016strategia_IO_proekt_dec.pdf

[2] A.A. Terekhova, "Topical issues of interaction of the basic sectors of the educational ecosystem in the labor market (on the example of the implementation of socially oriented projects)" [Aktual'nyye interesy osnovnykh sektorov obrazovatel'noy ekosistemy na rynke truda (na realizatsii sotsial'no-oriyentirovannykh proyektov)], Professional orientation [Professional'naya oriyentatsiya], 2019, vol. 1, pp. 66-69. (In Russ.).

[3] N.U. Fominykh, E.I. Koikova, 
A.V. Bubenchikova, "Educational environment as an ecosystem", World of Science, Culture, Education, 2021, vol. 3(88), pp. 292-294. (In Russ.). DOI: 10.24412/1991-5497-2021-388292-294

[4] O.E. Permyakov, E.A. Kitin, "Methodology of strategic planning for the development of educational ecosystems", Administrative Consulting, 2020, vol. 11(143), pp. 119-129. (In Russ.). DOI: 10.22394/1726-1139-2020-11119-129

[5] O.E. Permyakov, T.A. Pavlova, "Multifactorial Management the Development of Universities Innovative Educational Ecosystems", Administrative Consulting, 2020, vol. 12(144), pp. 149-164. (In Russ.). DOI: 10.22394/17261139-2020-12-149-164

[6] N.V. Dyorina, L.I. Savva, E.I. Rabina, "University ecosystem as an ecological vector of higher education", World of Science. Pedagogy and Psychology, 2020, vol. 8(3), p. 5. (In Russ.).

[7] P. Luksha, D. Spencer-Keyes, D. Cubista, "Educational ecosystems: developing practice for future education", Skolkovo Moscow School of Management, 2020. (In Russ.).

[8] E. Sjolie, A. Stromme, J. Boks-Vlemmix, "Team-skills training and real-time facilitation as a means for developing student teachers' learning of collaboration", Teaching and Teacher Education, 2021, vol. 107(4), p. 103477 DOI: $10.1016 /$ j.tate.2021.103477

[9] A. Jamaludin, D.W. Hung, "Digital learning trails: Scaling technology-facilitated curricular innovation in schools with a rhizomatic lens", Educ Change, 2016, vol. 17, pp. 355-377. DOI: 10.1007/s10833-016-9280-X

[10] S. Panda, "University and Teacher Education", Handbook on Teacher Education, 2021. DOI: 10.13140/RG.2.2.18546.63689

[11]H. Ucar, A. Bozkurt, O. Zawacki-Richter, "Academic procrastination and performance in distance education: a causal-comparative study in an online learning environment", Turkish Online Journal of Distance Education, 2021, vol. 22(4), pp. 13-23. DOI: 10.17718/tojde.1002726

[12]R. Ilahi, I. Widiaty, "Fuzzy system application in education", IOP Conference Series: Materials Science and Engineering, 2018, vol. 434(1), p. 012308. DOI: 1088/1757899X/434/1/012308
[13]E. Álvarez-Arregui, "Evolución de la Universidad en la Sociedad del Aprendizaje y la Enseñanza. El valor de las competencias en el desarrollo profesional y personal", Aula Abierta, 2019, vol. 48(4), pp. 349-372. (In Spanish). DOI: 10.17811/rifie.48.4.2019.349-372

[14] V.L. Kvint, "The concept of strategizing", Kemerovo: Kemerovo State University, 2020, 170 p. (In Russ.). DOI: 10.21603/978-5-83532562-7

[15] V.L. Kvint, V.V. Okrepilov, "Quality of life and values in national development strategies", Herald of the Russian Academy of Sciences, 2014, vol. 84(3), pp. 188-200. DOI: $10.1134 / \mathrm{S} 1019331614030058$

[16] A.A. Kozyrev, "Study of methodological basis of strategizing of social and economic development", Russian Journal of Industrial Economics, 2020, vol. 4, pp. 434-447. (In Russ.). DOI: 10.17073/2072-1633-2020-4-434-447

[17] V.L. Kvint, "On the choice of priorities" [O vybore prioritetov], Budget, 2016, vol. 11, pp. 78-81. (In Russ.).

[18]H. Liu, S. Kulturel-Konak, A. Konak, "Key Elements and Their Roles in Entrepreneurship Education Ecosystem: Comparative Review and Suggestions for Sustainability", Sustainability, 2021, vol. 13(19), p. 10648. DOI: $10.3390 / \mathrm{su} 131910648$

[19]F. Benita, D. Virupaksha, E. Wilhelm, B. Tuncer, "A smart learning ecosystem design for delivering Data-driven Thinking in STEM education", Smart Learn. Environ, 2021, vol. 8(1). DOI: 10.1186/s40561-021-00153-y

[20]I. Kozikoglu, N. Albayrak, "Teachers' Attitudes and the Challenges They Experience Concerning Individualized Education Program (IEP): A Mixed Method Study", Participatory Educational Research, 2021, vol. 9(1), pp. 98115. DOI: 10.17275/per.22.6.9.1

[21] K.N. Valdés, S.Q. Alpera, L.M. Cerdá Suárez, "An Institutional Perspective for Evaluating Digital Transformation in Higher Education: Insights from the Chilean Case", Sustainability, 2021, vol. 13(17), p. 9850. DOI: $10.3390 /$ su 13179850

[22]E.A. Shmeleva, "Innovative educative universe of an institute of higher education: field of development", Scientific Search: Personality, Education, Culture, 2012, vol. 1, p. 14-17. (In Russ.). 